\title{
Повышение конкурентоспособости организации на основе самооценки
}

\author{
О. С. Щукин ${ }^{1 凶}$, М. Н. М. Збун ${ }^{2}$, А. В. Шамиин ${ }^{3}$ \\ 1,2, 3 Воронежский государственный университет, Университетская пл., 1, \\ 394018, Воронеж, Российская Федерация
}

Для цитирования: Щукин О. С., Збун М. Н. М., Шамшин А. В. Повышение конкурентоспособости организации на основе самооценки // Вестник Воронежского государственного университета. Серия: Экономика и управление. 2021. № 1. C. 86-93. DOI 10.17308/econ.2021.1/3213

\begin{abstract}
Предмет. В статье рассматривается современный метод повышения конкурентоспособности организации на основе самооценки ее деятельности. Методология самооценки базируется на общепризнанных моделях делового совершенства, в нашей стране это модель премии правительства РФ в области качества, которая соответствует Европейской модели делового совершенства Европейского фонда по менеджменту качества (EFQM). Модель оценивает как организация, используя свои возможности, добивается запланированных результатов.

Цель. Анализ инструментов самооценки организации в задачах определения слабых и сильных сторон в деятельности, а также согласования возможностей организации с ее миссией и целями. Методология. В исследовании применялась совокупность научных подходов: системного, проектного, институционального, структурного. В работе использованы приемы и методы формальной и диалектической логики.

Результаты. Показаны основные подходы к управлению конкурентоспособности на основе инновационных, маркетинговых, качественных и финансовых показателей. Проведено сравнение критериев премии правительства РФ в области качества с классическими теориями конкурентоспособности и японского подхода к конкурентоспособности организации. Показано преимущество методологии самооценки по критериям премии правительства РФ в области качества в оценке нефинансовых показателей деятельности, таких как лидерство, удовлетворенность персонала, удовлетворенность потребителей.
\end{abstract}

Ключевые слова: самооценка, сравнение, показатели, оценка.

\section{Введение}

В современной рыночной экономике успешность функционирования организации определяется ее конкурентоспособностью. Продукция и услуги многих российских организаций не выдерживают конкуренции с зарубежными производителями. Развитие российской экономики напрямую связано с повышением конкурентоспособности отечественных организаций $[6 ; 11 ; 26 ; 27 ; 28]$. Поэтому российской экономической науке необходимо выявлять новые подходы к управлению конкурентоспособностью организации.

Теорию конкурентоспособности начали разрабатывать классики менеджмента, например, А. Смит, Д. Рикардо, Э. Хек-шер, Б. Олин. Значительный вклад в решение проблем кон- курентоспособности организации внесли теоретические работы И. Ансоффа и М. Портера.

Определение конкурентоспособности организации многогранно, рассмотрим мнения российских ученых. Г. Л. Азоев, П. С. Завьялов, Л.Ш. Лозовский определяют ее через конкуренцию на рынке аналогичных товаров через качество, цену [6]. В. Хруцкий и И. Корнеева также акцентируют внимание на конкурентоспособной продукции [2]. Согласно Г. Киперману конкурентоспособность организации - это способность противостоять на рынке другим производителям по степени удовлетворения потребностей всех заинтересованных сторон [9]. Данный подход очень близок к концепции Всеобщего менеджмента качества (далее - TQM). Многие современные российские исследователи рассма-

(c) Щукин О. С., Збун М. Н. М., Шамшин А. В. , 2021

Вестник ВГУ. Серия: Экономика и управление. 2021. № 1. С. 86-93. 
тривают конкурентоспособность организации в аналогичном ключе $[1 ; 3 ; 6 ; 10 ; 11 ; 12 ; 13 ; 15$; $16 ; 19 ; 21 ; 22]$. Р. Фатхутдинов делает акцент на способности организации выпускать конкурентоспособную продукцию [20]. Он вводит понятие конкурентного преимущества на основе категории «ценность». Мы считаем, что такой ценностью организации должна стать категория «качество».

Во всех подходах к анализу и оценке конкурентоспособности организации рассматриваются факторы, характеризующие конечные результаты, полученные организацией, такие как продукция, положение на рынке, финансовое положение и т. п.

В научной среде наметился переход рассмотрения теоретических исследований от конкурентоспособности продукции к конкурентоспособности организации, поэтому последняя стала занимать главенствующее место в теории конкурентоспособности.

Конкурентоспособность организации невозможно рассматривать в отрыве от категории «качество». Существует множество определений качества, рассмотрим экономический подход к данной категории. В современной экономической литературе определения качества однозначно соответствуют многочисленным определениям конкурентоспособности. Удовлетворение потребностей является главенствующей задачей менеджмента качества, призванной устранить неудовлетворенность потребительского спроса. Мы считаем, что в настоящее время качество является основополагающим элементом развития конкурентоспособности организации. Особый акцент на качества делает японский менеджмент. В теориях конкурентоспособности организации качество рассматривается применительно к продукции, но в настоящее время качестве необходимо рассматривать в отношении ко всей организации, к качеству процессов, качеству менеджмента.

Рассматривая существующие теоретические наработки в области конкурентоспособности организации, нужно отметить недостаточно проработанный момент использования методологии TQМ в теории конкурентоспособности. Методология TQM формирует качественный менеджмент организации, который определяет конкурентоспособность организации.

Мы определяем конкурентоспособность организации как процесс эффективного управления конкурентными преимуществами организации на основе TQM с целью реализации стратегических целей хозяйственно-финансо- вой деятельности и удовлетворения социально-экономических потребностей всех заинтересованных сторон [25].

\section{Исследование и обсуждение результатов}

Одним из основных инструментом TQM является самооценка организации, которая предполагает всесторонний и систематический анализ деятельности организации на основе лучших мировых практик для выявления ее сильных и слабых сторон, а также помогает руководству установить приоритеты, планирование и внедрение улучшений для достижения устойчивого успеха [4].

Методология самооценки опирается на лучшие мировые теоретические и практические разработки, представленные в национальных премиях в области качества $[14 ; 18 ; 24]$. В нашей стране это премия Правительства РФ в области качества (www.roskachestvo.gov.ru/ award) [18]. Данная модель совершенствования деятельности организации содержит 9 критериев и 32 подкритерия, которые распределены по двум группам: «возможности» и «результат». В основу положена модель делового совершенства Европейского фонда по менеджменту качества (далее - EFQM), которая оценивает, как организация, используя свои возможности, добивается запланированных результатов. Конечная цель самооценки - определение слабых и сильных сторон в деятельности организации. Это позволяет спланировать мероприятия, позволяющие привести возможности организации в соответствие с ее миссией и целями. Самооценка охватывает всю деятельность организации с вовлечением всех ее работников, развивает творчество в коллективе, позволяет предоставить данные о состоянии организации на основе четких количественных критериев и выявить, насколько она соответствует своему предназначению. Используя признанные мировые модели делового совершенства, самооценка позволяет позиционировать свою организацию среди конкурентов.

Охватывая все направления деятельности организации, методология самооценки отдает предпочтение нефинансовым факторам. Преуспевающие, конкурентоспособные организации отличаются нефинансовыми факторами, к которым относятся лидерские качества руководителя, преданность персонала и потребителя. Этим факторам руководство ведущих мировых организаций стало уделять больше 
внимания. Финансовые факторы в модель премии Правительства РФ в области качества составляют не более 7,5 \% оценки. Самооценка организации неотделима от кроссдиагности, позволяющей выявлять слабые стороны в деятельности организации.

Опираясь на методологию самооценки, можно сказать, что конкурентоспособность организации - это демонстрация стабильного, долговременного результата за счет эффективного использования возможностей организации.

Сравнивая методологию самооценки организации с классическими теориями конкурентоспособности, можно сказать, что ни одна из основных теорий конкурентоспособности меркантилизма (Т. Маен, А. Монкретьен и др.), стоимости (А. Смит, Д. Рикардо, Дж. Милль), равновесия (А. Маршалл), эволюционная (И. Шумпетер), конкурентных преимуществ (М. Портер), интеллектуального лидерства (Г. Хамел, К. Прахалад) - не рассматривает ответственность руководства так, как самооценка деятельности на основе премии Правительства РФ в области качества [18; 24]. Лидирующая роль руководства рассматривается по пяти позициям: определение руководителями предназначения организации, стратегии ее развития и ценностей, демонстрация на личном примере; участие руководителей в деятельности, обеспечивающей разработку, внедрение и постоянное совершенствование системы менеджмента организации; участие руководителей в работе с потребителями, партнерами и представителями общества; мотивация, поддержка и поощрение руководителями персонала организации; определение и поддержка руководителями инноваций и перемен в организации [18].

Конкурентоспособность организации определяется многими факторами. Государство совместно с организациями формирует только потенциальные конкурентные преимущества. Реальные конкурентные преимущества сформировать и реализовать могут только организации [8; 25]. Государство создает условия для повышения конкурентоспособности организации, которая в свою очередь принимает решение о выборе сегмента рынка и товара. Учитывая емкость, покупательскую способность, характер потребностей на выбранном сегменте рынка, организация определяет масштаб, себестоимость производства, а также качество товара.

К факторам, определяющим конкурентоспособность организации, можно отнести: макроэкономический уровень - конкурентоспособность страны; отраслевой уровень - конкурентоспособность отрасли; уровень организации - качество менеджмента организации.

Самым главным показателем качества менеджмента является авторитет руководителя и его команды, руководитель должен быть лидером, за которым следуют его команда и все сотрудники. Это так называемые нефинансовые показатели, характеризующие преуспевающую организацию.

Среди факторов конкурентных преимуществ организации можно выделить случайные, обусловленные появлением благоприятной ситуации, не вызванные непосредственно деятельностью организации, и конкурентные, целенаправленно формируемые менеджментом организации. Мы будем рассматривать вторую группу факторов, которые формируют долговременные, устойчивые конкурентные преимущества организации высокого порядка. Данные конкурентные преимущества определяются многими факторами. Большинство экономистов к основному фактору относят инновационную деятельность в технологии, продукте, организации производства.

Мы считаем, что к основным факторам в настоящее время необходимо отнести нематериальные факторы, связанные с человеком, персоналом организации, начиная от высшего менеджмента и заканчивая простыми работниками, так называемые мягкие показатели, поэтому качество менеджмента становится основополагающим в конкурентоспособности организации, что полностью соответствует концепции TQM.

В Японии для оценки конкурентоспособности организации выделяют следующие пять групп факторов. Первая группа определяет долю рынка, которую занимает организация. Вторая - способность к развитию потенциала производственных, инновационных и сбытовых мощностей организации. Третья - эффективную стратегию организации, которая должна быть направлена не только на сохранение и расширения доли рынка, но и получение синергетического эффекта, многократно повышающего экономическую эффективность организации. Четвертая группа факторов касается способности высшего менеджмента организации эффективно управлять организацией. Пятая - отражает результаты деятельности организации за несколько лет.

Опираясь на концепцию TQM, в качестве инструмента повышения конкурентоспособ- 
ности организации мы выбираем методологию самооценки организации [18; 24; 25], которая основывается на модель премии Правительства РФ в области качества. В настоящее время эта модель полностью соответствует EFQM [18].

Сравнение японского подхода к конкурентоспособности организации с моделью премии Правительства РФ в области качества приведено в таблице.

Из таблицы видно, что в японском подходе отсутствует персонал организации, который составляет основу нематериальных факторов. Нематериальные факторы на современном этапе развития экономики определяют конкурентоспособность организации, поэтому методология самооценки организации является более эффективным инструментом управления.

\section{Заключение}

В практической экономике высшее руководство большое внимание уделяет финансовой информации о деятельности организаций. Это объясняется традиционным подходом к формированию планов, отчетов, государствен- ной статистики. В настоящее время ученые, практики начинают обращаться к нефинансовой информации, отражающей влияние человеческого фактора на эффективность управления организацией.

Исследование информированности топ-менеджеров и членов совета директоров, проведенное в западных организациях, показало отсутствие у высшего руководства большинства организаций нефинансовой информации о своей организации. Больше половины руководителей организаций отмечают недостаток только финансовой информации для успешного управления организацией. Три четверти руководителей согласны с использованием нефинансовой информации в эффективном управлении организацией. При этом они считают такую информацию жизненно важной и соответствующей требованиям современного конкурентного рынка. Исследование показало отсутствие у большинства топ-менеджеров и членов совета директоров знаний, как можно получить и использовать нефинансовую информацию в практике управления.

Т а б л ц ц Сравнение японского подхода к конкурентоспособности организации с моделью Премии Правительства РФ в области качества

\begin{tabular}{|c|c|c|c|c|c|c|c|c|c|}
\hline \multirow[b]{2}{*}{$\begin{array}{c}\text { Японский подход к конкурентоспо- } \\
\text { собности организации }\end{array}$} & \multicolumn{9}{|c|}{ Критерии модели самооценки } \\
\hline & 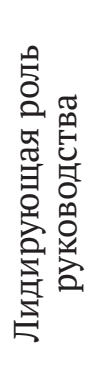 & 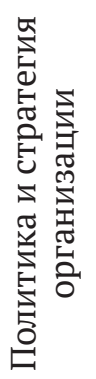 & 胥 & 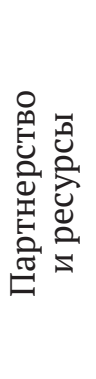 & 壳鴶 & 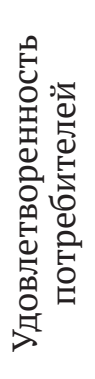 & 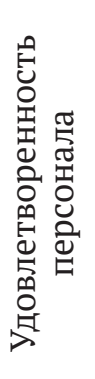 & 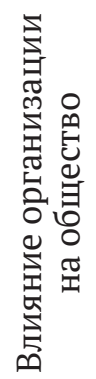 & 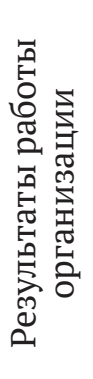 \\
\hline $\begin{array}{l}\text { 1. Доля рынка, которую занимает } \\
\text { организация }\end{array}$ & & + & & & & + & & & \\
\hline $\begin{array}{l}\text { 2. Способность к развитию потен- } \\
\text { циала производственных, иннова- } \\
\text { ционных и сбытовых мощностей } \\
\text { организации }\end{array}$ & + & + & & & + & & & & \\
\hline $\begin{array}{l}\text { 3. Эффективная стратегия органи- } \\
\text { зации, которая должна быть на- } \\
\text { правлена не только на сохранение и } \\
\text { расширения доли рынка, но и полу- } \\
\text { чения синергетического эффекта }\end{array}$ & & + & & + & & & & & \\
\hline $\begin{array}{l}\text { 4. Способности высшего менед- } \\
\text { жмента организации эффективно } \\
\text { управлять организацией }\end{array}$ & + & & & & + & & & + & + \\
\hline $\begin{array}{l}\text { 5. Результаты деятельности органи- } \\
\text { зации за несколько лет }\end{array}$ & & & & & & + & & + & + \\
\hline
\end{tabular}


Эту проблему необходимо решать применением новых инструментов и методик в управлении организацией. Предлагаемая нами методология самооценки организации позволяет предоставить руководству организации достоверную нефинансовую информацию, получаемую на основе использования мировых практик. Самооценка организации является современным инструментом менеджмента, позволяющим повысить эффективность деятельности по совершенствованию организации и повышению ее конкурентоспособности.

Методология самооценки предоставляет руководству реальные данные о состоянии организации, формирует регулярный менеджмент на основе четких количественных критериев, позиционирует организацию среди конкурентов, охватывает все аспекты деятельности организации и вовлекает всех ее работников.

Методология самооценки опирается на модель премии Правительства РФ в области качества. Нефинансовая информация формируется в процессе оценки по следующим критериям и подкритериям модели: лидирующая роль руководства; развертывание и доведение до сведения персонала политики и стратегии в рамах ключевых процессов; персонал; информация и знания; менеджмент и улучшение взаимоотношений с потребителями; удовлетворенность потребителей качеством продукции; удовлетворенность персонала; влияние организации на общество. Максимальный балл, который можно получить по этим критериям, равен 615. Финансовые показатели работы организации набирают 75 баллов. Высококачественные нефинансовые показатели в модели делового совершенства охватывают практически все аспекты работы с персоналом и потребителем и превосходят финансовые в 8,2 раза. Необходимо отметить, что значимость финан-

\section{Библиографический список}

1. Баженов Ю. В. Методологические аспекты к представлению сущности понятия «конкуренция» // Тенденции развития науки и образования. 2017. № 22-2. С. 7-10.

2. Балабанова Л., Петухова В. Как измерить конкурентоспособность //Торговля. 2014№ 1 (6).С. 73-75.

3. Горяйнова Е. С. Мониторинг конкурентоспособности имиджа предприятий // Управление в современных системах. 2017. № 2 (13). С. 10-17.

4. ГОСТ Р ИСО 9004-2019 «Менеджмент качества. Качество организации. Руководство по достижению устойчивого успеха организации». совых показателей для организации не подвергается сомнению.

Методология самооценки существенно повышает конкурентоспособность организации при соблюдении следующих принципов:

- согласование методов и процессов самооценки с обычной деятельностью и управленческими процессами в организации;

- определение руководством, в каких конкретных мероприятиях, в какой степени и в какой форме оно должно прямо принимать участие. Основной критерий - сложность выполняемых действий и их важность для организации;

- согласование различных процессов самооценки организации;

- управление самооценкой включает различные аспекты - технологические, структурные, методические, человеческие, психологические, политические, финансовые и иные. Это, пожалуй, больше всего затрудняет выполнение обязанностей руководством, так как в процессе участвуют специалисты, которые часто пытаются навязать свой ограниченный взгляд на оцениваемую проблему;

- управление самооценкой включает решения о применении различных подходов и способов вмешательства, которые помогают правильно начать, систематически вести работу, справляться с сопротивлением персонала, добиваться поддержки и осуществлять необходимые перемены.

Самооценка организации - это измерение организации. Невозможно изменить и совершенствовать то, что не измеряешь. Невозможно сказать, где вы находитесь или куда движетесь без измерения. Измерения должны быть понятны каждому работнику и относиться ко всем видам деятельности организации, особенно к тем, которые считаются самыми приоритетными для организации.

5. Гребенщикова И. Д. Предпринимательство и конкурентоспособность региона. Конкурентный потенциал развития Российской Федерации в условиях нового технологического уклада // Материалы Междунар. науч.-практ. конф., посвящ. памяти заслуж. экономиста Рос. Федерации, д-ра экон. наук, проф. Р. М. Гусейнова, 2015. С. 103-107.

6. Грушенко В. И. Формирование стратегии высокой конкурентоспособности в условиях стратегических изменений во внешней среде // Университетский вестник Смоленского гуманитарного университета. 2015. № 2 (16). С. 54-57. 
7. Завьялов П. С. Маркетинг в схемах, рисунках, таблицах : учеб. пособие. М. : ИНФРА-М, 2016496 с.

8. Киперман Г. Я., Сурганов Б. С. Современный экономический словарь. М. : Экономика, 2012. 255 с.

9. Козлова О.И. Механизм реализации системы управления конкурентоспособностью предприятия и производимой продукции // Аллея Науки. 2017. № 5. С. 146-149.

10. Колесников М. В., Лымарева О. А. Теоретические аспекты понятия конкуренция. Конкурентоспособность Российской Федерации // Стратегия импортозамещения: проблемы, тенденции, перспективы (на примере Краснодарского края) : материалы регион. науч. конф., 2017. С. 62-64.

11. Лосева А. Ю., Третьякова Ю. В., Сычева А. В. Конкурентоспособность предпринимательских структур // Теория и практика актуальных научных исследований : сборник научных статей. Волгоград : Изд-во ВГТУ, 2017. С. 110-113.

12. Мабиала Ж., Примышев И. Н., Фоменко Ю. О. Конкурентоспособность предприятия и характеристика параметрических подходов к ее оценке // World science: problems and innovations : сборник статей победителей VII Междунар. науч.-практ. конф. Пенза : Наука и Просвещение, 2017. С. 91-96.

13. Минигалеева К. И. Управление конкурентоспособностью предпринимательских структур в современных условиях // Международный научно-исследовательский журнал. 2017. № 7-1. С. 22-24.

14. Могилко Д. Ю. Самооценка организационного совершенства по критериям премии правительства РФ в области качества // Мотивация и оплата труда. 2020. № 3. С. 228-241.

15. Мухина Е. Р. Исследование методов оценки конкурентоспособности хозяйствующего субъекта // Международный научно-исследовательский журнал. 2015. № 2-3 (33). С. 58-59.

16. Петрова А. Д., Блаженкова Н. М. Альянс ШОС и БРИКС как средство повышения конкурентоспособности предпринимательского сектора Россий- ской Федерации в рамках ВТО // Экономика и предпринимательство. 2015. № 9 (2). С. 946-950.

17. Поршнев А. Г., Азоев Г. Л. Маркетинг : учебное пособие. М. : Финстатинформ, 2013. 93 с.

18. Р 50-601-45/1-2006 «Самооценка деятельности организации на соответствие критериям Премий Правительства Российской Федерации в области качества 2006 года».

19. Тарануха Ю. В. Модификация конкурентного принципа в процессе эволюции конкуренции // Общество и экономика. 2017. № 3-4. С. 49-67.

20. Фатхутдинов Р. А. Управление конкурентоспособностью продукции. М. : Эксмо, 2004. С. 192.

21. Хисаева А. И., Петрова А. Д. Управление конкурентоспособностью предпринимательских структур в современных условиях // Экономика и управление: научно-практический журнал. 2015. №5 (127). С. 52-55.

22. Хотинская Г. И., Беликов Д. Л. Моделирование конкурентоспособности российских компаний сферы услуг (финансовый аспект) // Маркетинг услуг. 2015. № 1. С. 2-10.

23. Щукин О. С., Гугелев А. В., Семченко А. А. Стандарты управления качеством для устойчивого развития административно-территориальных образований // Вестник Воронежского государственного университета. Серия: Экономика и управление. 2018. № 4. С. 118-124.

24. Щукин О. С. Самооценка деятельности организации по центрированной модели : концептуально-методологические основы адаптивного подхода: монография. Воронеж : Воронеж. гос. ун-т, 2007. 295 с.

25. Щукин О. С., Збун М. Самооценка организации в методологии конкурентоспособности // Вестник СГСЭУ. 2020. № 2. С. 47-51.

26. Ящин Н. С. Конкурентоспособность промышленного предприятия: методология, оценка, регулирование: монография. Саратов : Изд. центр Саратовской государственной экономической академии 1997. 248 с.
Олег Семенович Щукин, доктор экономических наук, профессор кафедры экономики труда и основ управления, Воронежский государственный университет, Воронеж, Российская Федерация

E-mail: oschukin@yandex.ru

ORCID ID: 0000-0002-4965-1002

Збун Мохаммед Н. М., аспирант кафедры экономики труда и основ управления, Воронежский государственный университет, Воронеж, Российская Федерация

E-mail: mz060616@gmail.com

ORCID ID: 0000-0001-7173-1175
Александр Викторович Шамшин, аспирант кафедры экономики труда и основ управления, Воронежский государственный университет, Воронеж, Российская Федерация

E-mail: shamshin-vrn@yandex.ru

ORCID ID: 0000-0002-7155-6212

Поступила в редакцию 29.12.2020

Подписана в печать 12.02.2021 


\title{
Improving the competitiveness of the organization based on self-assessment
}

\author{
O. S. Schukin ${ }^{1 凶}$, M. N. M. Zbun' ${ }^{2}$ A. V. Shamshin ${ }^{3}$ \\ 1,2,3 Voronezh State University, 1 University sq., 394018, Voronezh, Russian Federation
}

Cite as: Schukin, O. S., Zbun, M. N. M., Shamshin, A. V. (2021) Improving the competitiveness of the organization based on self-assessment. Proceedings of the Voronezh State University. Series: Economics and Management. 1, 86-93. (In Russ., abstract in Eng.). DOI: 10.17308/econ.2021.1/3213

Importance. The article considers a modern method of increasing the competitiveness of an organization based on self-assessment of its activities. The methodology of self-assessment is based on generally recognized models of business excellence, in our country it is the model of the Russian Government award in the field of quality, which corresponds to the European Model of Business Excellence of the European Foundation for Quality Management (EFQM). The model evaluates how the organization, using its capabilities, achieves the planned results.

Objectives. Analysis of the organization's self-assessment tools in identifying strengths and weaknesses in activities, as well as aligning the organization's capabilities with its mission and goals.

Methods. In the process of achieving the set goals, a set of scientific approaches was used: systemic, project-based, institutional, and structural. The work uses the techniques and methods of formal and dialectical logic.

Results. The main approaches to the management of competitiveness based on innovative, marketing, quality and financial indicators are shown. The criteria of the Russian government award in the field of quality are compared with the classical theories of competitiveness and the Japanese approach to the competitiveness of the organization. The advantage of the methodology of self-assessment according to the criteria of the Russian government award in the field of quality in the assessment of soft performance indicators, such as leadership, staff satisfaction, customer satisfaction, is shown.

Key words: self-assessment, comparison, indicators, evaluation.

\section{Conflict of Interest}

The authors declare the absence of obvious and potential conflicts of interest related to the publication of this article.

\section{References}

1. Bazhenov, Yu. V. (2017) Methodological aspects to the representation of the essence of the concept of "competition". Trends in the development of science and education. 22-2, 7-10. (In Russian).

2. Balabanova, L. \& Petukhova, V. (2014) How to measure competitiveness. Trade. 1 (6), 73-75. (In Russian).

3. Goryainova, E. S. (2017) Monitoring the competitiveness of the image of enterprises. Management in modern systems. 2 (13), 10-17. (In Russian).

4. ISO 9004:2018 «Quality management - Quality of an organization - Guidance to achieve sustained success», IDT.

5. Grebenshchikova, I. D. (2015) Entrepreneurship and competitiveness of the region. Competitive potential of the development of the Russian Federation in the conditions of a new technological way. Materi- als of the International Scientific and Practical conference dedicated to the memory of the Honored Economist of the Russian Federation, Doctor of Economic Sciences, Professor R. M. Huseynov. 103-107. (In Russian).

6. Grushenko, V. I. (2015) Formation of the strategy of high competitiveness in the conditions of strategic changes in the external environment. University Bulletin of the Smolensk Humanitarian University. 2 (16), 54-57. (In Russian).

7. Zavyalov, P. S. (2016) Marketing in schemes, figures, tables. Moscow, INFRA-M publ. (In Russian).

8. Kiperman, G. Ya., \& Surganov, B. S. (2012) [Modern economic dictionary]. Moscow. Ekonomika. (In Russian)

9. Kozlova, O. I. (2017) [Mechanism of implementation of the enterprise competitiveness management system and manufactured products]. Alley of Science. 5, 146-149. (In Russian). 
10.Kolesnikov, M. V. \& Lymareva, O. A. (2017) [Theoretical aspects of the concept of competition. Competitiveness of the Russian Federation]. Import substitution strategy: problems, trends, prospects (on the example of the Krasnodar Territory) Materials of the regional scientific conference. 62-64. (In Russian).

11. Loseva, A. Yu., Tretyakova, Yu. V. \& Sycheva, A.V. (2017) [Competitiveness of business structures]. [Theory and practice of actual scientific research. Collection of scientific articles]. Volgograd, VSTU Publishing House. 110-113. (In Russian).

12. Mabiala, Zh., Primyshev, I. N., \& Fomenko, Yu. O. (2017) [Competitiveness of the enterprise and characteristics of parametric approaches to its assessment]. [Collection of articles of the winners of the VII International Scientific and Practical Conference].Penza, Science and Education publ. 91-96. (In Russian).

13. Minigaleeva, K. I. (2017) Management of competitiveness of business structures in modern conditions. International Research Journal. 7-1, 22-24. (In Russian).

14. Mogilko, D. Yu. (2020) Self-assessment of organizational excellence according to the criteria of the award of the Government of the Russian Federation in the field of quality. Motivation and remuneration. 3 , 228-241. (In Russian).

15. Mukhina, E. R. (2015) Research of methods for assessing the competitiveness of an economic entity. International Research Journal. 2-3 (33), 58-59. (In Russian).

16. Petrova, A.D., \& Blazhenkova, N. M. (2015) The SCO and BRICS Alliance, as a means of improving the competitiveness of the Russian Federation's business sector within the WTO. Economics and Entrepreneurship. 9 (2), 946-950. (In Russian).

17. Porshnev, A. G. \& Azoev, G. L. (2013) Marketing. Moscow, Finstatinform. (In Russian).
18. P 50-601-45/1-2006 Recommendations. Self-assessment of the organization's activities for compliance with the criteria for premiums of the Government of the Russian Federation in the field of quality 2006 (for organizations with more than 250 employees). (In Russian).

19. Taranukha, Yu. V. (2017) Modification of the competitive principle in the process of competition evolution. Society and Economy. 3-4, 49-67.(In Russian).

20.Fatkhutdinov, R. A. (2004) [Management of product competitiveness]. Moscow, Eksmo Publishing House. (In Russian).

21.Khisaeva, A. I. \& Petrova, A.D. (2015) Management of competitiveness of business structures in modern conditions. Economics and Management. 5 (127), 52-55. (In Russian).

22. Khotinskaya, G. I. \& Belikov, D. L. (2015) Modeling the competitiveness of Russian companies in the service sector (financial aspect). Marketing of services. 1, pp. 2-10. (In Russian).

23. Schukin, O. S., Gugelev, A. V. \& Semchenko, A. A. (2018) The quality management standards for the sustainable development of administrative-territorial formations. Proceedings of Voronezh State University. Series: Economics and Management. 4, 118-124. (In Russian).

24. Shchukin, O. S. (2007) Self-assessment of the organization's activities according to the centered model: conceptual and methodological foundations of the adaptive approach. Voronezh, Voronezh St. Univ. Publ. (In Russian).

25. Shchukin, O. S. \& Zbun, M. (2020) Self-assessment of the organization in the methodology of competitiveness. Bulletin of the SSSEU.2, 47-51.(In Russian).

26. Yashin, N. S. (1997) Competitiveness of an industrial enterprise: methodology, assessment, regulation. Saratov, Saratov St. Economic Academy Publ.(In Russian).
Oleg S. Schukin, Dr. Sci. (Econ.), Prof., Labour Economy and Management Department, Voronezh State University, Voronezh, Russian Federation E-mail: oschukin@yandex.ru ORCID ID: 0000-0002-4965-1002

Mohammad N. M. Zbun, post-graduate student of the Labour Economy and Management Department, Voronezh State University, Voronezh, Russian Federation

E-mail:mz060616@gmail.com

ORCID ID: 0000-0001-7173-1175
Alexander V. Shamshin, post- graduate student of the Labour Economy and Management Department, Voronezh State University, Voronezh, Russian Federation

E-mail: shamshin-vrn@yandex.ru

ORCID ID: 0000-0002-7155-6212

Received 29.12.2020

Accepted 12.02.2021 